\title{
A method to measure heat flux in convection using Gardon gauge
}

\author{
Tairan Fu [1,*], Anzhou Zong [1], Yirui Zhang [1], Hua Sheng Wang [2]
}

[1] Key Laboratory for Thermal Science and Power Engineering of Ministry of Education, Beijing Key Laboratory of $\mathrm{CO}_{2}$ Utilization and Reduction Technology, Department of Thermal Engineering, Tsinghua University, Beijing 100084, P.R. China

[2] School of Engineering and Materials Science, Queen Mary University of London, London E1 4NS, UK

\section{* Corresponding author: trfu@mail.tsinghua.edu.cn}

\begin{abstract}
Heat flux measurements are widely used in thermal environment analyses. The Gardon gauge is an excellent heat flux sensor with a wide measurement range and long lifespan in harsh environments. However, the Gardon gauge is usually calibrated for radiation heat transfer and is not good for convective heat transfer. This paper introduces a method to measure heat flux for convective heat transfer using the Gardon gauge by relating the measurement sensitivity for convection to that for radiation. The heat flux and convective heat-transfer coefficient can then be simultaneously determined by the standard thermo-electromotive voltage output of the Gardon gauge. The method was demonstrated for convective heat-transfer coefficient ranging from 200 to $3000 \mathrm{~W} /\left(\mathrm{m}^{2} \mathrm{~K}\right)$. The analysis illustrates that the measurement sensitivity for convection decreases with increasing convective heat-transfer coefficient. A correction is necessary especially for higher convective heat-transfer coefficient. The corrected convective heat-transfer coefficients and heat fluxes agree well with the actual values. The relative uncertainty in heat flux is within $0.64 \%$. The method not only greatly improves the measurement accuracy of the Gardon gauge for convection applications, but also provides a reference for evaluating convective heat transfer coefficients in convection environments.
\end{abstract}

Keywords: Heat flux, convection, convective heat-transfer coefficient, Gardon gauge

\section{Introduction}

Heat flux measurements are important in many practical applications [1-5]. In micro-electric systems, increasing working efficiency and higher frequency of semiconductor devices require accurate measurement of the heat flux of heat dissipated by the devices [6-9]. Heat flux during turbulent flow, supercritical fluid flow and boiling is an important parameter [10-15]. Early study by Puits et al. [10] measured the local heat flux in highly turbulent Rayleigh-Bénard convection in air at the heating/cooling plate using commercial sensors. In fire safety system, convection is most important in the early stage of fire for activating thermal alarms and sprinklers, therefore there is a great need to experimentally investigate convection heat transfer in fire applications [16-20]. Vega et al. [18] used a hybrid heat flux gauge to quantify the thermal boundary condition of a surface exposed to fire.

Heat flux measurements for convective heat transfer are widely used in applications with harsh thermal environments including high enthalpy plasmas, high pressure arc heaters, high power pulsed lasers and structural thermal tests [21-32]. However, heat flux distribution measurements in high pressure, high temperature and hypersonic flows are still extremely difficult. Kiddet et al. [22] developed a fast response heat flux sensor based on a modified Schmidt-Boelter gauge for heat flux measurements in hypersonic wind tunnels. Carlomagno and Cardone [29-31] used infrared thermography for convective heat transfer measurements in complex fluid flows from natural convection to hypersonic flow. IR thermography is a powerful optical tool and can be successfully exploited to determine convective heat flux distributions with both steady and transient techniques. Liu et al. [32] proposed an analytical inverse method to calculate heat flux distribution using a time sequence of temperature sensitive paint images acquired in the quiet Mach 6 Ludwieg tube, in which the temperature sensitive paint colors were measured on a 7-deg half-angle sharp circular metal cone to evaluate the measurement accuracy.

Commercial Gardon gauges are available with metal bodies, blackbody sensor foils and water cooling designs for high heat flux measurements with long lifespan in harsh environments [33-38]. Gardon gauges were first introduced to 
measurement of heat flux for radiation and are usually only calibrated for radiation. The voltage output of the Gardon gauge is approximately linearly proportional to the incident heat flux when measuring thermal radiation and the standard radiation sources are the optimal choice for calibrating the heat flux gauge. However, the heat flux gauges should be calibrated in an environment close to the actual environment and heat flux gauges calibrated using radiation sources may not be appropriate for measuring heat flux for convection [39-44].

Although Gardon gauges have been extensively studied, they are rarely used to measure convective heat transfer due to large uncertainty. This paper presents a measurement method, using the Gardon gauge calibrated by radiation source, which can simultaneously obtain heat flux and convective heat-transfer coefficient.

\section{Method}

\subsection{Measurement sensitivity}

The Gardon heat flux gauge is a diffusion type of heat flux gauge with a circular constantan foil coated with a diffuse, absorbing coating attached to a copper heat sink. When the Gardon gauge is used to measure radiation flux, the thermal radiation is uniformly incident onto the gauge foil surface, and there is a temperature gradient in the radial direction so that the metal leads attached to the foil center and the edge form a thermocouple joint. The voltage output of the Gardon gauge from this thermocouple joint is linearly proportional to the incident heat flux in the steady-state heat flux conditions. The ratio of the voltage output to the measured heat flux is defined as the measurement sensitivity of the heat flux gauge $[33,38]$. The measurement sensitivity obtained for radiation is approximately constant, but is unsuitable to convective heat transfer measurements [39-41].

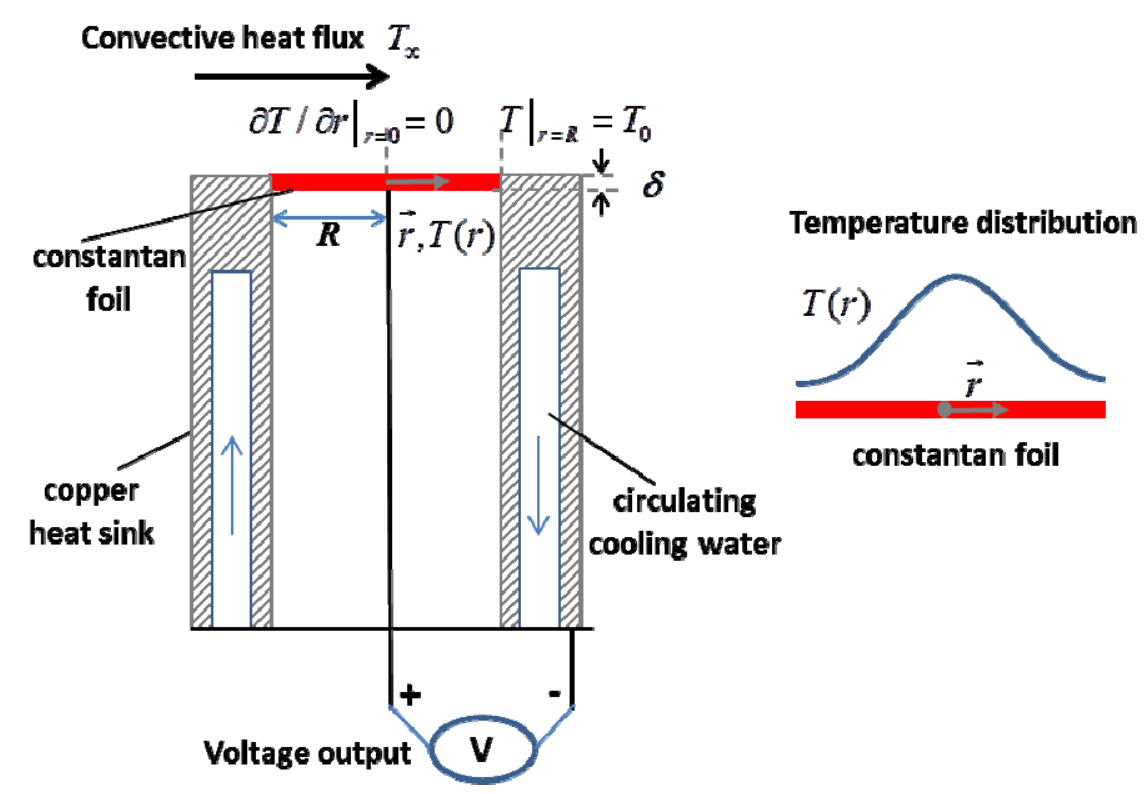

Fig. 1 Sketch of the Gardon heat flux gauge for convective heat transfer measurements

Figure 1 shows a sketch of convective heat transfer measurements using a Gardon heat flux sensor. The steady state heat conduction equation together with the boundary conditions describing the radial temperature distribution in the foil exposed to a heat flux can be expressed as $[33,38]$ :

$$
\left\{\begin{array}{l}
\frac{1}{r} \frac{\partial}{\partial r}\left(\lambda r \frac{\partial T(r)}{\partial r}\right)+\frac{q}{\delta}=0 \\
\left.T\right|_{r=R}=T_{0}, \partial T /\left.\partial r\right|_{r=0}=0
\end{array}\right.
$$

where $r$ is the distance measured from the center in the radial direction in the foil, $T(r)$ is the temperature at position $r$ on the foil surface, $T_{0}$ is the temperature of the heat sink, $\delta$ is the foil thickness and $R$ is the radius of the constantan foil. $q$ is the heat flux at the foil surface due to convective or radiative heat transfer. For convection heat transfer, $q=h\left(T_{\infty}-T(r)\right) . T_{\infty}$ is the temperature of fluid flowing over the foil surface, $h$ is the convective heat-transfer 
coefficient. $T_{0}$ and $T_{\infty}$ are generally measured by thermocouples. $\lambda$ is the thermal conductivity of the constantan foil and is expressed as a linear function of temperature:

$$
\lambda=\lambda_{0}\left(1+b\left(T-T_{0}\right)\right)
$$

where $\lambda_{0}=20.9 \mathrm{~W} /\left(\mathrm{m}^{\circ} \mathrm{C}\right)$ at $T_{0}=0^{\circ} \mathrm{C}$ and $b=0.00231^{\circ} \mathrm{C}^{-1}$ for a temperature range of $0 \sim 200^{\circ} \mathrm{C}[33]$.

To simplify the analysis based on Eq. (1), the temperature dependence of the thermal conductivity is neglected meaning that the thermal conductivity is assumed to be uniform at different radial positions on the foil surface. Then, the thermal conductivity of the foil is described with the average temperature over the radius of the foil as:

$$
\lambda=\lambda_{0}\left(1+b\left(\bar{T}-T_{0}\right)\right)=\xi \lambda_{0}
$$

where $\bar{T}$ is the average temperature over the radius of the foil, $\bar{T}=\left(T_{r=0}+T_{0}\right) / 2$. $\xi$ is defined as $1+b\left(\bar{T}-T_{0}\right)$ and is relative to the average temperature of the foil.

The theoretical expression of the foil surface temperature can be obtained by solving Eqs. (1) and (3):

$$
T=T_{0}+\left(T_{\infty}-T_{0}\right)\left(1-I_{0}\left(m_{\xi} r\right) / I_{0}\left(m_{\xi} R\right)\right)
$$

where $I_{0}$ is the zeroth order Bessel function and $m_{\xi}=\left(h / \xi \lambda_{0} \delta\right)^{1 / 2} \cdot m_{\xi}$ is the function of the convective heat transfer coefficient, $h$, and the parameter, $\xi$.

The convective heat flux on the foil surface, $q_{c}$, is obtained by Eq. (4):

$$
q_{c}=\frac{\int_{0}^{R} h\left(T_{\infty}-T\right) 2 \pi r d r}{\pi R^{2}}=\frac{2 h}{m_{\xi} R} \frac{I_{1}\left(m_{\xi} R\right)}{I_{0}\left(m_{\xi} R\right)-1} \Delta T
$$

where $I_{1}$ is the first order Bessel function and $\Delta T$ is the temperature difference between the center and the edge of the constantan foil, $\Delta T=T_{r=0}-T_{0}$.

The thermo-electromotive voltage output, $E$, of the copper-constantan thermocouple formed by the Gardon gauge is expressed by a function of the temperature difference, $\Delta T$ :

$$
E=k \Delta T(1+g \Delta T)
$$

where the coefficients of $k$ and $g$ of the copper-constantan thermocouple are known as $k=0.0381 \mathrm{mV} /{ }^{\circ} \mathrm{C}$ and $g=0.0012{ }^{\circ} \mathrm{C}^{-1}[33]$.

The measurement sensitivity for the convective heat flux, $L_{c}$, is defined as the ratio of the voltage output, $E$, to the measured convective heat flux, $q_{c}$, so $L_{c}$ from Eqs. (5) and (6) is:

$$
L_{c}=\frac{E}{q_{c}}=k(1+g \Delta T) \frac{m_{\xi} R\left(I_{0}\left(m_{\xi} R\right)-1\right)}{2 h I_{1}\left(m_{\xi} R\right)}
$$

Equation (7) shows that the measurement sensitivity for the convective heat flux is relative to $m_{\xi}, \Delta T$ and $h$. It is well known that the convective heat-transfer coefficient is an important quantity to affect the measurement sensitivity.

However, The measurement sensitivity, $L_{r}$, for radiative heat flux measurements in traditional Gardon gauge applications differs from $L_{c}$. Assuming constant radiative heat flux and constant thermal conductivity, $L_{r}$ is determined as [33]:

$$
L_{r}=k R^{2} / 4 \lambda_{0} \delta
$$

The Gardon gauges are commonly calibrated by the standard blackbody source [45-47]. The gauges are irradiated by the known radiative heat flux from the blackbody source. The measurement sensitivity, $L_{r}$, is then experimentally obtained by the ratio of the gauge voltage output to the irradiative heat flux value which is calculated by the StefanBoltzmann law using measured blackbody temperature [45-47].

As a comparison, the ratio of the measurement sensitivities in convection and radiation, $F$, is given by: 


$$
F=\frac{L_{c}}{L_{r}}=2 \frac{I_{0}\left(m_{\xi} R\right)-1}{m_{\xi} R I_{1}\left(m_{\xi} R\right)}
$$

Figure 2 shows the difference between $L_{c}$ and $L_{r}$ illustrated by the distribution of the ratio $F$ for various values of $m_{\xi} R$, where $m_{\xi} R$ is a function of the convective heat transfer coefficient, $h$. A larger $m_{\xi} R$ indicates a higher convective heat transfer. $L_{c}$ is smaller than $L_{r}$. The ratio $F$ decreases from 1.0 to 0.53 as $m_{\xi} R$ increases from 0 to 4.0 , indicating that the measurement sensitivity for convection decreases with increasing convective heat-transfer coefficient. A correction to the measurement sensitivity for convection is therefore needed with the known measurement sensitivity for radiation.

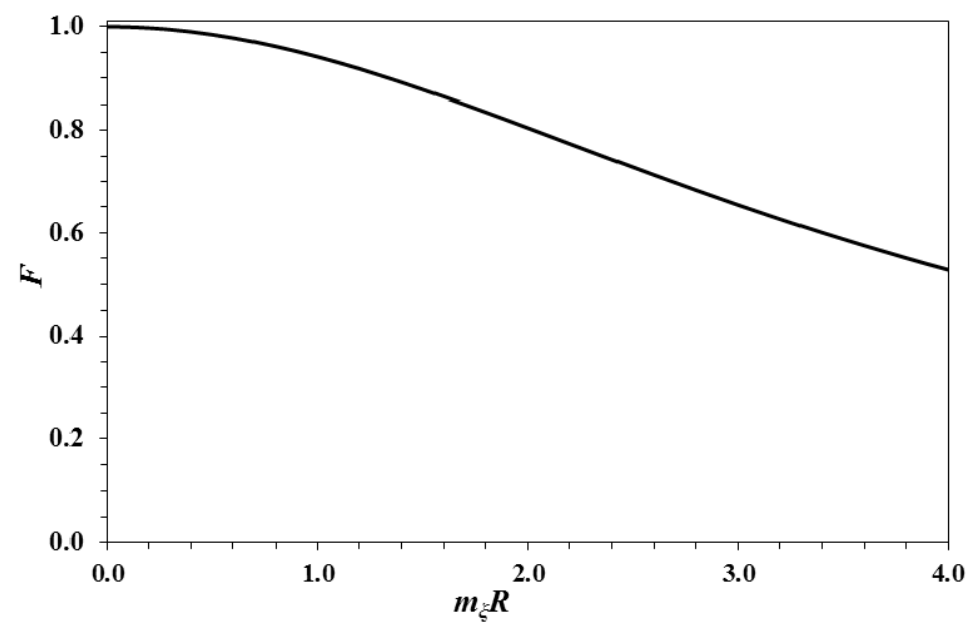

Fig. 2 Convection to radiation convection factor

\subsection{Determination of heat flux and heat-transfer coefficient for convective heat transfer}

In a convection environment, if the convective heat-transfer coefficient at the foil surface of the gauge is known (that is, $m_{\xi} R$ is known), the measurement sensitivity of heat flux in convection can be related to that in radiation. The determination of heat-transfer coefficient or $m_{\xi} R$ is important for heat flux measurement in convection using Gardon gauge calibrated in radiation. Some previous studies have addressed that the convective heat-transfer coefficient needs to be measured or evaluated as the measurement prerequisite [39-41]. However, accurate prediction of the convective heat-transfer coefficient is still complex and difficult. An improved measurement method is proposed following the procedure below to simultaneously determine both convective heat-transfer coefficient and heat flux.

A. The temperature difference, $\Delta T$, between the center and the edge of the constantan foil is first obtained from the gauge voltage output, $E$, using Eq. (6). Then the foil center temperature, $T_{r=0}$, is obtained from $\Delta T$.

B. Equation (4) relates the center temperature, $T_{r=0}$, to $m_{\xi} R$, so $m_{\xi} R$ can be directly determined from $T_{r=0}$ using Eq. (4).

C. The convection measurement sensitivity, $L_{c}$, is then obtained based on the calculated $m_{\xi} R$ and the radiation sensitivity $L_{r}$ using Eq. (9) and Fig. 2. The heat flux in convection is then determined using :

$$
q_{c}=E / L_{c}=E / F L_{r}
$$

D. The convective heat-transfer coefficient can then be determined using $m_{\xi} R$ obtained in step B.

Thus, this method allows a Gardon gauge calibrated in radiation to be used as a heat flux sensor in convection without any other instrument adjustments. The merit of the method is that it gives not only the heat flux but also the convective heat-transfer coefficient at the foil surface, and the measurement accuracy of the Gardon gauges is much better in convection applications. 


\section{Method example}

The measurement method was demonstrated by the calculations. The parameters of the Gardon gauge were $\delta=0.2$ $\mathrm{mm}, R=2.5 \mathrm{~mm}$, and a heat sink temperature of $T_{0}=0^{\circ} \mathrm{C}$. The standard measurement sensitivity for heat flux in radiation was obtained using the theoretical analysis [38] as $L_{r}=0.0145 \mathrm{mV} /\left(\mathrm{kW} / \mathrm{m}^{2}\right)$. All Gardon gauges are calibrated by manufacturers. The temperature, $T_{\infty}$, of the gases flowing over the foil surface was assumed to be $700 \mathrm{~K}$ and the convective heat-transfer coefficient was assumed to be 200,500, 1000, 1500, 2000, 2500, and 3000 W/( $\left.\mathrm{m}^{2} \mathrm{~K}\right)$, representing different convection cases. The corresponding heat flux was then calculated and applied to the foil surface of the Gardon gauge as the "true" heat flux, $q_{c, \text { true }}$. The gauge output voltages for the various convection conditions were calculated using Eqs. (5) and (6) and are reported as the "notional experimental values".

The heat flux calculated using the "notional" output voltage and the standard measurement sensitivity, $L_{r}$, for the heat flux in radiation is defined as the "apparent" heat flux, $q_{\text {appa }}$, while neglecting the calibration difference between the radiation and convection heat transfer calibrations. The convection heat flux calculated using the method introduced in section 2.2 based on the "notional" output voltage and the corrected measurement sensitivity, $L_{c}$, is defined as the "corrected" heat flux, $q_{c a l}$.

The distributions of $m_{\xi} R$ and $F$ calculated for convection heat-transfer coefficients of $(200,3000) \mathrm{W} /\left(\mathrm{m}^{2} \mathrm{~K}\right)$ using Eqs. (4) (9) are shown in Fig. 3 as calculated from the "notional" output voltages of the Gardon gauge. $m_{\xi} R$ increases from 0.55 to 1.88 as the convective heat-transfer coefficient, $h$, increases from 200 to $3000 \mathrm{~W} /\left(\mathrm{m}^{2} \mathrm{~K}\right)$ while $F$ decreases from 0.98 to 0.825 . $F$ reflects the differences in the measurement sensitivities between convection and radiation. Figure 4 shows the calculated results for $L_{r}$ and $L_{c}$ based on Eq. (9) for the various convection heat-transfer coefficients. Although the standard measurement sensitivity, $L_{r}$, remains the same, the calibrated measurement sensitivity for convection measurements decreases from $0.0143 \mathrm{mV} /\left(\mathrm{kW} / \mathrm{m}^{2}\right)$ to $0.0118 \mathrm{mV} /\left(\mathrm{kW} / \mathrm{m}^{2}\right)$ for increasing convective heat-transfer coefficients in the range of $(200,3000) \mathrm{W} /\left(\mathrm{m}^{2} \mathrm{~K}\right)$, demonstrating that as the convection changes, the convection measurement sensitivity needs to be adjusted. The relationship of $L_{c}$ and $h$ could be built into the conversion method when the non-linear relationship of $h$ and $m_{\xi} R$ is determined for all cases with a large range of heat flux in convection.

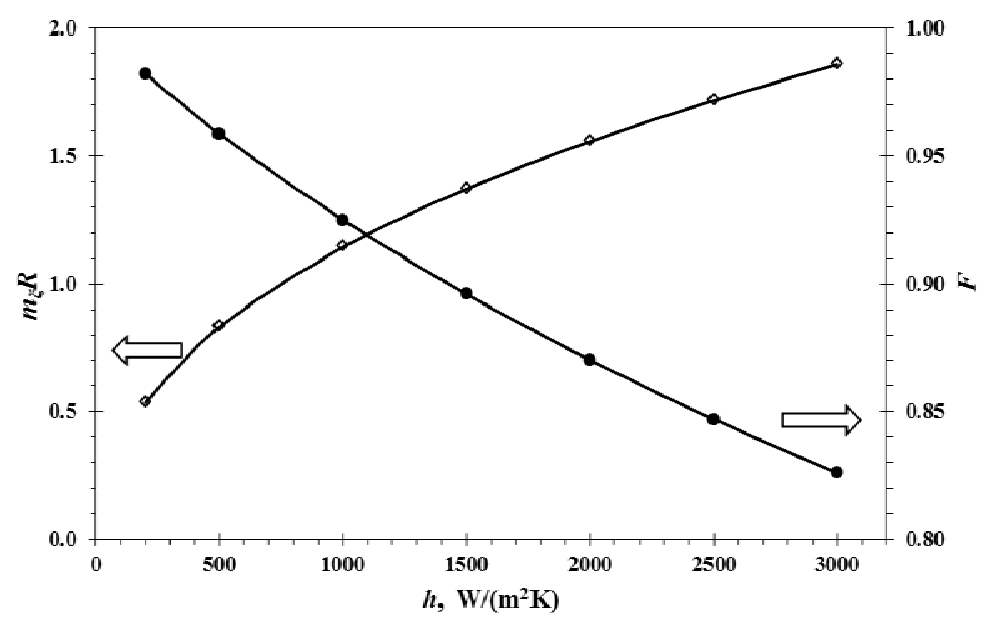

Fig. 3 Distributions of $m_{\xi} R$ and $F$ for various convective heat-transfer coefficients 


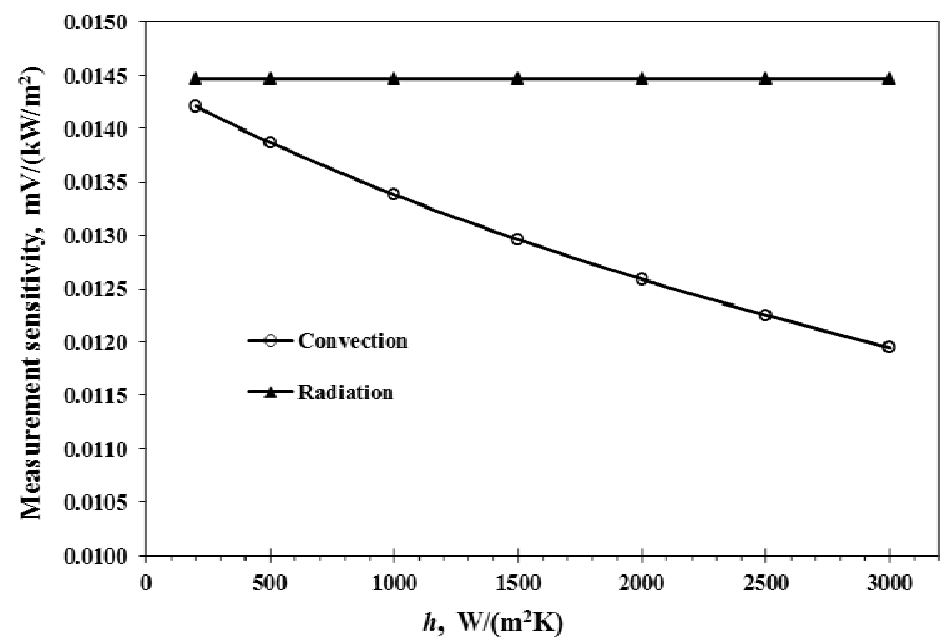

Fig. 4 Radiation and convection measurement sensitivities for various convective heat-transfer coefficients

Figure 5 shows the "true" heat flux in convection, $q_{c, \text { true }}$, the "apparent" heat flux, $q_{\text {appa }}$, obtained from the standard measurement sensitivity, and the "corrected" heat flux, $q_{c a l}$, obtained using the calibrated measurement sensitivity for convection, and the relative errors of $\left(q_{\text {appa }}-q_{c, \text { true }}\right) / q_{c, \text { true }}$ and $\left(q_{c a l}-q_{c, \text { true }}\right) / q_{c, \text { true }}$ at various convective heat-transfer coefficients. The results show that $q_{\text {appa }}$ differs from $q_{c, \text { true }}$, especially for higher convective heat-transfer coefficients and higher heat fluxes. When $h$ is $3000 \mathrm{~W} /\left(\mathrm{m}^{2} \mathrm{~K}\right), \quad q_{c, \text { true }}$ is $898.4 \mathrm{~kW} / \mathrm{m}^{2}, q_{\text {appa }}$ is $746.7 \mathrm{~kW} / \mathrm{m}^{2}$ and the relative error, $\left|\left(q_{\text {appa }}-q_{c, \text { true }}\right) / q_{c, \text { true }}\right|$, reaches $16.9 \%$. This difference between $q_{c, \text { true }}$ and $q_{\text {appa }}$ is caused by the fact that the radiation measurement sensitivity is not suitable for convection measurements. However, this difference is significantly decreased for lower convective heat-transfer coefficients which may be approximately neglected. For example, when $h \leq 500 \mathrm{~W} /\left(\mathrm{m}^{2} \mathrm{~K}\right),\left|\left(q_{\text {appa }}-q_{c, \text { true }}\right) / q_{c, \text { true }}\right|$ is less than $4.3 \%$. The phenomenon can be explained using the results in Fig. 4 that the sensitivity difference between $L_{c}$ and $L_{r}$ decreases with decreasing convective heat-transfer coefficient.

The corrected heat flux, $q_{c a l}$, agrees well with the "true" heat flux in convection, $q_{c, \text { true }}$, and the relative error $\left|\left(q_{c a l}-q_{c, \text { true }}\right) / q_{c, \text { true }}\right|$ is very small, within $(0.1 \%, 0.64 \%)$ for convective heat-transfer coefficients of $(200,3000)$ $\mathrm{W} /\left(\mathrm{m}^{2} \mathrm{~K}\right)$. In the example demonstration of the method, there is no "notional experimental errors" on the "notional experimental values". Therefore, the small difference between $q_{c a l}$ and $q_{c, \text { true }}$ should arise from the approximate assumption of the thermal conductivity in Eq. (3). In fact, the thermal conductivity at different radius positions on the foil surface is different due to the temperature dependence of the thermal conductivity across the foil. However, the assumption of the thermal conductivity represented by the average temperature over the radius of the foil can simplify the theoretical analysis to derive a simple, clear expression of Eq. (4). The small error arising from the thermal conductivity is acceptable in engineering applications so that the assumption of the thermal conductivity in the method is reasonable.

Thus, this analysis illustrates that the convection correction is necessary for higher convective heat-transfer coefficients when using the Gardon gauge and that this convective heat flux greatly improves the Gardon gauge measurement accuracy for convection applications, especially in strong convection environments. 


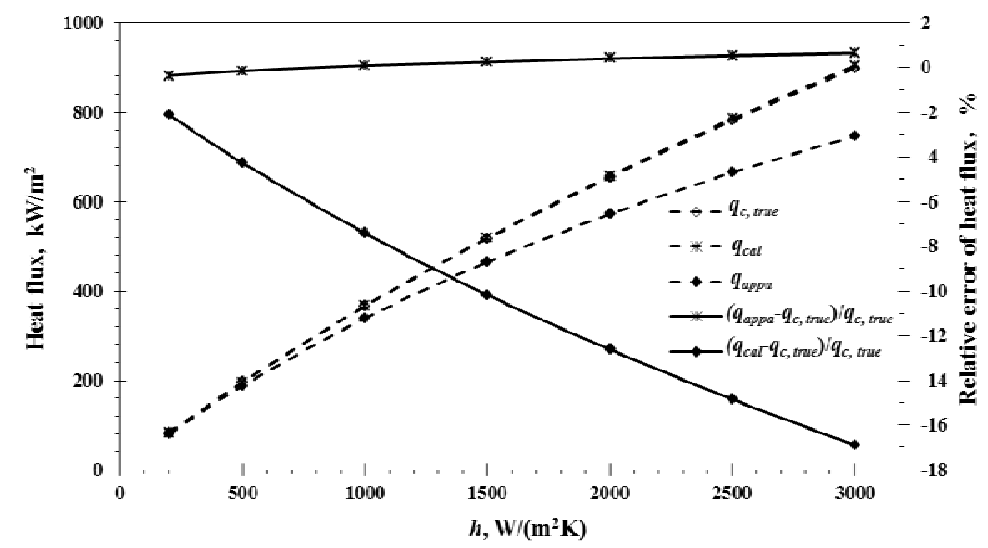

Fig. $5\left(q_{c, \text { true }}, q_{\text {appa }}, q_{c a l}\right)$ and relative errors at various convective heat-transfer coefficients

The calculated $m_{\xi} R$ in Fig. 3 were then used to determine the convective heat-transfer coefficients shown in Fig. 6.

The calculated results also agree well with the actual convective heat-transfer coefficients. The absolute error in the convective heat-transfer coefficients slightly increases with increasing convective heat-transfer coefficient while the relative error decreases with increasing convective heat-transfer coefficient, with a maximum relative error of only $3.5 \%$. The error of convective heat-transfer coefficients shown in Fig. 6 only relates to the error in the assumption of the thermal conductivity in Eq. (3). Therefore, the demonstration calculations show that using this method a Gardon gauge can be used to evaluate convective heat-transfer coefficients within an acceptable accuracy.

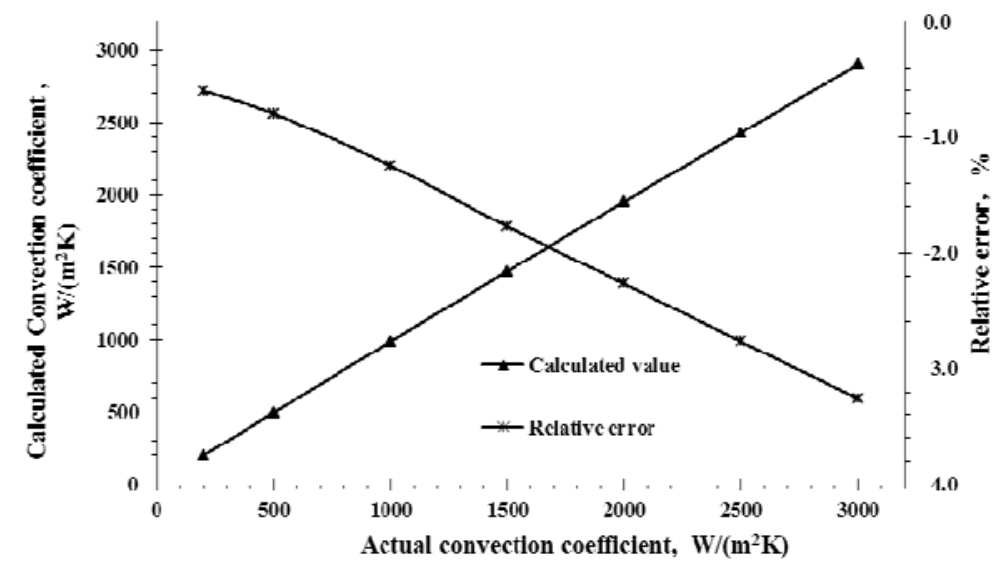

Fig. 6 Calculated convective heat transfer coefficients

\section{Conclusions}

Gardon gauges have been widely used to measure heat flux in radiation. Their accuracy to measure heat flux in convection was not satisfactory since the gauges are calibrated using radiation sources. This work presents a method to use Gardon gauges to measure heat flux in convection based on a relationship between the measurement sensitivities in convection and radiation. A simple expression of the foil surface temperature is theoretically obtained by assuming that the thermal conductivity of the gauge foil is determined by its average temperature. The analysis shows that the convective heat-transfer coefficient and heat flux can be simultaneously determined from the Gardon gauge voltage output without any other instrument adjustments. The method is demonstrated by calculations which show that the convection measurement sensitivity decreases with increasing convective heat-transfer coefficient. The convection correction is especially important when using the Gardon gauge in strong convection environments. The calculated convective heat-transfer coefficients and heat fluxes agree well with the "true" values with the relative error in heat flux within $0.64 \%$ for convective heat-transfer coefficient in the range of 200 to $3000 \mathrm{~W} /\left(\mathrm{m}^{2} \mathrm{~K}\right)$ and the maximum relative error in convective heat-transfer coefficient within $-3.5 \%$. Compared with the conventional use of Gardon gauges for 
heat flux measurement in radiation, the method can be used to improve the measurement accuracy of Gardon gauges for convection applications as well as to provide a reference for evaluating convective heat transfer measurements.

\section{Acknowledgements}

This work was supported by the National Natural Science Foundation of China (No. 51576110), the Science Fund for Creative Research Groups of the National Natural Science Foundation of China (No. 51321002) and the Program for New Century Excellent Talents in University (NCET-13-0315).

\section{References}

[1] M. Khaled, F. Harambat, H. Peerhossaini, Underhood thermal management: Temperature and heat flux measurements and physical analysis, Applied Thermal Engineering, 30(2010) 590-598.

[2] X. Li, X. Huai, J. Cai, F. Zhong, X. Fan, Z. Guo, Convective heat transfer characteristics of China RP-3 aviation kerosene at supercritical pressure, Applied Thermal Engineering, 31(2011) 2360-2366.

[3] M. Geron, C. Butler, J. Stafford, D. Newport, Development and validation of a compact thermal model for an aircraft compartment, Applied Thermal Engineering, 61(2013) 65-74.

[4] R.P. Mooney, S. McFadden, Z. Gabalcová, J. Lapin, An experimental-numerical method for estimating heat transfer in a Bridgman furnace, Applied Thermal Engineering, 67(2014) 61-71.

[5] A. Cebula, J. Taler, Determination of transient temperature and heat flux on the surface of a reactor control rod based on temperature measurements at the interior points, Applied Thermal Engineering, 63(2014) 158-169.

[6] D. Iero, F. Corte, G. Fiorentino, P. Sarro, B. Morana, Heat flux sensor for power loss measurements of switching devices: IEEE, 2013, 327-330

[7] E. Chiavazzo, L. Ventola, F. Calignano, D. Manfredi, P. Asinari, A sensor for direct measurement of small convective heatfluxes: Validation and application to micro-structured surfaces, Experimental Thermal and Fluid Science, 55 (2014) 42-53

[8] B.Jasperson, J. Schmale, W. Qu, F. Pfefferkorn, K.Turner, Thin film heat flux sensors fabricated on copper substrates for thermal measurements in microfluidic environments, J.Micromech.Microeng.,24 (2014) $125018(11 \mathrm{pp})$

[9] Z. Azizi, A. Alamdari, M.R. Malayeri, Convective heat transfer of $\mathrm{Cu}$-water nanofluid in a cylindrical microchannel heat sink, Energy Conversion and Management, 101 (2015) 515-524

[10] R. Puits, C. Resagk, A. Thess, Measurements of the instantaneous local heat flux in turbulent Rayleigh-Bénard convection, New Journal of Physics, 12 (2010) 075023 (13pp)

[11] E. Lee, H. Kang, Y Kim, Flow boiling heat transfer and pressure drop of water in a plate heat exchanger with corrugated channels at low mass flux conditions, International Journal of Heat and Mass Transfer, 77 (2014) $37-$ 45

[12] G. Choi, B. Kim, H. Lee, S. Shin, H. Cho, Jet impingement in a crossflow configuration: Convective boiling and local heat transfer characteristics, International Journal of Heat and Fluid Flow, 50 (2014) 378-385

[13] R. Kaiser, R. Puits, Local wall heat flux in confined thermal convection, International Journal of Heat and Mass Transfer, 73 (2014) 752-760

[14] G.J. McGranaghan, A.J. Robinson, The mechanisms of heat transfer during convective boiling under the influence of AC electric fields, International Journal of Heat and Mass Transfer,73(2014): 376-388

[15] A. Parwani, P. Talukdar, P. Subbarao, Estimation of boundary heat flux using experimental temperature data in turbulent forced convection flow, Heat Mass Transfer (2015) 51:411-421

[16] P. Veloo1, J. Quintiere, Convective heat transfer coefficient in compartment fires, Journal of Fire Sciences, 31(5) 410-423, 2013

[17] F. Morandini, Y. Perez-Ramirez, V. Tihay, P. Santoni, T. Barboni, Radiant, convective and heat release characterization of vegetation fire, International Journal of Thermal Sciences, 70 (2013) 83-91

[18] T. Vega, B. Lattimer, T. Diller, Fire thermal boundary condition measurement using a hybrid heat flux gage, Fire Safety Journal, 2013, 61: 127 137

[19] T. Vega, R.Wasson, Partitioning measurements of convective and radiative heat flux, International Journal of Heat and Mass Transfer, 84 (2015) 827-838

[20] E.A. Sullivan, A.G. McDonald, Mathematical model and sensor development for measuring energy transfer from wildland fires, International Journal of Wildland Fire 2014, 23, 995-1004

[21] C.A. Powars, W.S. Kennedy, R.A. Rindal, Heat Flux Measurement Using Swept Null Point Calorimetry, Journal 
of Spacecraft and Rockets, 1972, 9(9): 668-672

[22] C.T. Kidd, J.C. Adams, Fast-Response Heat-Flux Sensor for Measurement Commonality in Hypersonic Wind Tunnels, Journal of Spacecraft and Rockets, 2001, 38(5): 719-729

[23] S. Löhle, J. Battaglia, J. Batsale, O. Enouf, J. Dubard, J. Filtz, Characterization of a heat flux sensor using short pulse laser calibration, Rev. Sci. Instrum., 2007: 78, 53501

[24] S. Löhle, J. Battaglia, P. Jullien, B.V. Ootegem, J. Lasserre,J Couzi, Improvement of High Heat Flux Measurement Using a Null-Point Calorimeter, Journal of Spacecraft and Rockets, 2008, 45(1): 76-81

[25] S. Löhle, J. Battaglia, Transient Heat Flux Measurements in High Enthalpy Air Plasma Flows Using a Non-Integer System Identification Approach, 41st AIAA Thermophysics Conference, 22-25 June 2009, San Antonio, Texas

[26] T. Roediger, H. Knauss, U. Gaisbauer, E. Kraemer, S. Jenkins,J. Wolfersdorf, Time-Resolved Heat Transfer Measurements on the Tip Wall of a Ribbed Channel Using a Novel Heat Flux Sensor-Part I: Sensor and Benchmarks, Journal of Turbomachinery, 2008, 130(1): 11018

[27] R.R. Parker, J.F. Klausner, R.W. Mei, Supersonic Two-Phase Impinging Jet Heat Transfer, Journal of heat transfer, 135/022201-1, 2013

[28] B. Kraetzig, D.R. Buttsworth, Temperature and Heat Flux Measurement on Hot Models in Short-Duration Facilities, Journal of Thermophysics and Heat Transfer. 29(1): 37-46, 2015

[29] T. Astarita, G. Cardone, G.M. Carlomagno, C. Meola, A survey on infrared thermography for convective heat transfer measurements, Optics \& Laser Technology, 32(7-8):593-610, 2000

[30] T. Astarita, G. Cardone, G.M. Carlomagno, Infrared thermography: An optical method in heat transfer and fluid flow visualisation, Optics and Lasers in Engineering,44(3-4):261-281, 2006

[31] G.M. Carlomagno, G. Cardone, Infrared thermography for convective heat transfer measurements, Experiments in Fluids, 49(6): 1187-1218, 2010

[32] T.S. Liu, , C.A.C. Ward, J. Rubal, J.P. Sullivan, S.P. Schneider, Heat-Flux Measurements with TemperatureSensitive Paint in a Mach-6 Quiet Tunnel, Journal of spacecraft and rockets, 50(2): 282-293, 2013

[33] R. Gardon, An instrument for the direct measurement of intense thermal radiation, Review of Scientific Instruments, 24(1953) 366-370.

[34] N.R. Keltner, M.W. Wildin, Transient response of circular foil heat-flux gauges to radiative fluxes, Review of Scientific Instruments, 46(1975) 1161-1166.

[35] A.M. Agnone, Transient Response of Thin Circular Foil Heat Flux Gauges-Back Radiation Effects, 41st AIAA Thermophysics Conference, 2009, AIAA 2009-4238

[36] C.A. Pullins, T.E. Diller, Direct Measurement of Hot-Wall Heat Flux, Journal of Thermophysics and Heat Transfer, 26(2012) 430-438.

[37] E. Guillot, I. Alxneit, J. Ballestrin, J.L. Sans, C. Willsh, Comparison of 3 heat flux gauges and a water calorimeter for concentrated solar irradiance measurement, Energy Procedia, 49(2014) 2090-2099.

[38] T.R. Fu, A.Z. Zong, J.B. Tian, C.Y. Xin, Gardon gauge measurements of fast heat flux transients, Applied Thermal Engineering, 100: 501-507, 2016

[39] B. Prasad, A. Mohanty, Analysis and calibration of a foil heat flux sensor for convective measurements, Journal of Physics E: Scientific Instruments, 1983, 16: 1095

[40] G.J. Borell, T.E. Diller, A convection calibration method for local heat flux gages, Journal of Heat Transfer, 1987, 109(1): 83-89

[41] C.H. Kuo, A.K. Kulkarni, Analysis of heat flux measurement by circular foil gages in a mixed convection/radiation environment. Journal of heat transfer, 1991, 113(4): 1037-1040

[42] A. Gifford, A. Hoffie, T. Diller, S. Huxtable, Convection calibration of Schmidt-Boelter heat flux gauges in stagnation and shear air flow, Journal of Heat Transfer, 2010, 132(3): 31601

[43] P. Stathopoulos, F. Hofmann, T. Rothenfluh, P.R. von Rohr, Calibration of a Gardon sensor in a high-temperature high heat flux stagnation facility, Experimental Heat Transfer, 25(2012) 222-237.

[44] R.L. Ash, Response characteristics of thin foil heat flux sensors, AIAA Journal, 1969, 7(12): 2332-2335

[45] W.M. Pitts, A.V. Murthy, J. L. de Ris, J. Filtz, K. Nygard, D. Smith, I. Wetterlund, Round robin study of total heat flux gauge calibration at fire laboratories, Fire Safety Journal, 2006, 41(6): 459-475

[46] A.V. Murthy, G.T. Fraser, D.P. Dewitt, Experimental In-Cavity Radiative Calibration of High Heat-Flux Meters, Journal of Thermophysics and Heat Transfer, 2006, 20(2): 327-335

[47] J.R. Filtz, T. Valin, J. Hameury, J. Dubard, New Vacuum Blackbody Cavity for Heat Flux Meter Calibration, International Journal of Thermophysics, 2009, 30(1): 236-248 